Research paper

\title{
Characterization of papain-like isoenzymes from latex of Asclepias curassavica by molecular biology validated by proteomic approach
}

\author{
Walter D. Obregón ${ }^{a}$, Constanza S. Liggieri ${ }^{a}{ }^{*}$, Sebastian A. Trejo ${ }^{b}$, Francesc X. Avilés ${ }^{b}$, \\ Sandra E. Vairo-Cavalli ${ }^{a}$, Nora S. Priolo ${ }^{a}$ \\ a Laboratorio de Investigación de Proteínas Vegetales, Departamento de Ciencias Biológicas, Facultad de Ciencias Exactas, Universidad Nacional de La Plata, \\ 47 y 115 s/N, C.C. 711, B1900AVW, La Plata, Argentina \\ ${ }^{\mathrm{b}}$ Institut de Biotecnologia i de Biomedicina, Universitat Autònoma de Barcelona, Campus Universitari 08193, Bellaterra, Cerdanyola del Vallès, Barcelona, Spain
}

\section{A R T I C L E I N F O}

\section{Article history:}

Received 13 March 2009

Accepted 31 July 2009

Available online 11 August 2009

\section{Keywords:}

Asclepias curassavica

Cysteine peptidase

Peptide mass fingerprint

Papain-like protease

Plant latex

\begin{abstract}
A B S T R A C T
Latices from Asclepias spp are used in wound healing and the treatment of some digestive disorders. These pharmacological actions have been attributed to the presence of cysteine proteases in these milky latices. Asclepias curassavica (Asclepiadaceae), "scarlet milkweed" is a perennial subshrub native to South America. In the current paper we report a new approach directed at the selective biochemical and molecular characterization of asclepain cI (acI) and asclepain cII (acII), the enzymes responsible for the proteolytic activity of the scarlet milkweed latex. SDS-PAGE spots of both purified peptidases were digested with trypsin and Peptide Mass Fingerprints (PMFs) obtained showed no equivalent peptides. No identification was possible by MASCOT search due to the paucity of information concerning Asclepiadaceae latex cysteine proteinases available in databases. From total RNA extracted from latex samples, CDNA of both peptidases was obtained by RT-PCR using degenerate primers encoding Asclepiadaceae cysteine peptidase conserved domains. Theoretical PMFs of partial polypeptide sequences obtained by cloning (186 and 185 amino acids) were compared with empirical PMFs, confirming that the sequences of 186 and 185 amino acids correspond to acI and acII, respectively. $\mathrm{N}$-terminal sequences of acI and acII, characterized by Edman sequencing, were overlapped with those coming from the cDNA to obtain the full-length sequence of both mature peptidases (212 and 211 residues respectively). Alignment and phylogenetic analysis confirmed that acI and acI belong to the subfamily C1A forming a new group of papain-like cysteine peptidases together with asclepain f from Asclepias fruticosa. We conclude that PMF could be adopted as an excellent tool to differentiate, in a fast and unequivocal way, peptidases with very similar physicochemical and functional properties, with advantages over other conventional methods (for instance enzyme kinetics) that are time consuming and afford less reliable results.
\end{abstract}

(c) 2009 Elsevier Masson SAS. All rights reserved.

\section{Introduction}

Latex is a milky fluid composed of a liquid serum containing, either in suspension or solution, a complex mixture of molecules [1]. It is clear that the latex performs its functions through multiple modes of action, ranging from physical barriers to toxicity and defense. Some plants immediately secrete latex when the leaves, stems or fruits are injured. The latex bleeding proceeds for a few minutes until a clot form around the wounded area. The coagulation process is vital for plant defense against possible pathogen attack. Latex may act to shield the cambial meristem and the contents of the sieve tubes from predators, or ward off parasites or

\footnotetext{
* Corresponding author. Tel.: +54 $2214230121 x 57$; fax: +54 2214226947.

E-mail address: cliggieri@biol.unlp.edu.ar (C.S. Liggieri).
}

pathogens. Therefore, it seems reasonable to assume that the substances and enzymes needed for such purposes are present in latex $[2,3]$. It is well known that several hydrolytic enzymes cellulases, polygalacturonases, chitinases, lipolytic and proteolytic enzymes - are highly expressed in laticifers $[2,4-6]$. The economic importance of some of these hydrolytic enzymes has prompted active investigations into its biochemical aspects.

Several names have been assigned to enzymes that cleave peptide bonds, including proteases, proteinases, peptidases, and proteolytic enzymes [7]. Here we will use the term peptidases (EC 3.4) as is suggested by the Nomenclature Committee of IUPAC-IUBMB (URL http:// www.chem.qmul.ac.uk/iubmb/enzyme/EC3/4/). Cysteine peptidases (EC 3.4.22) are widely distributed in nature and are divided into clans that do not share sequence or structural identity and probably arose from different evolutionary lines. They have a common catalytic mechanism that involves a nucleophilic cysteine thiol in a catalytic 


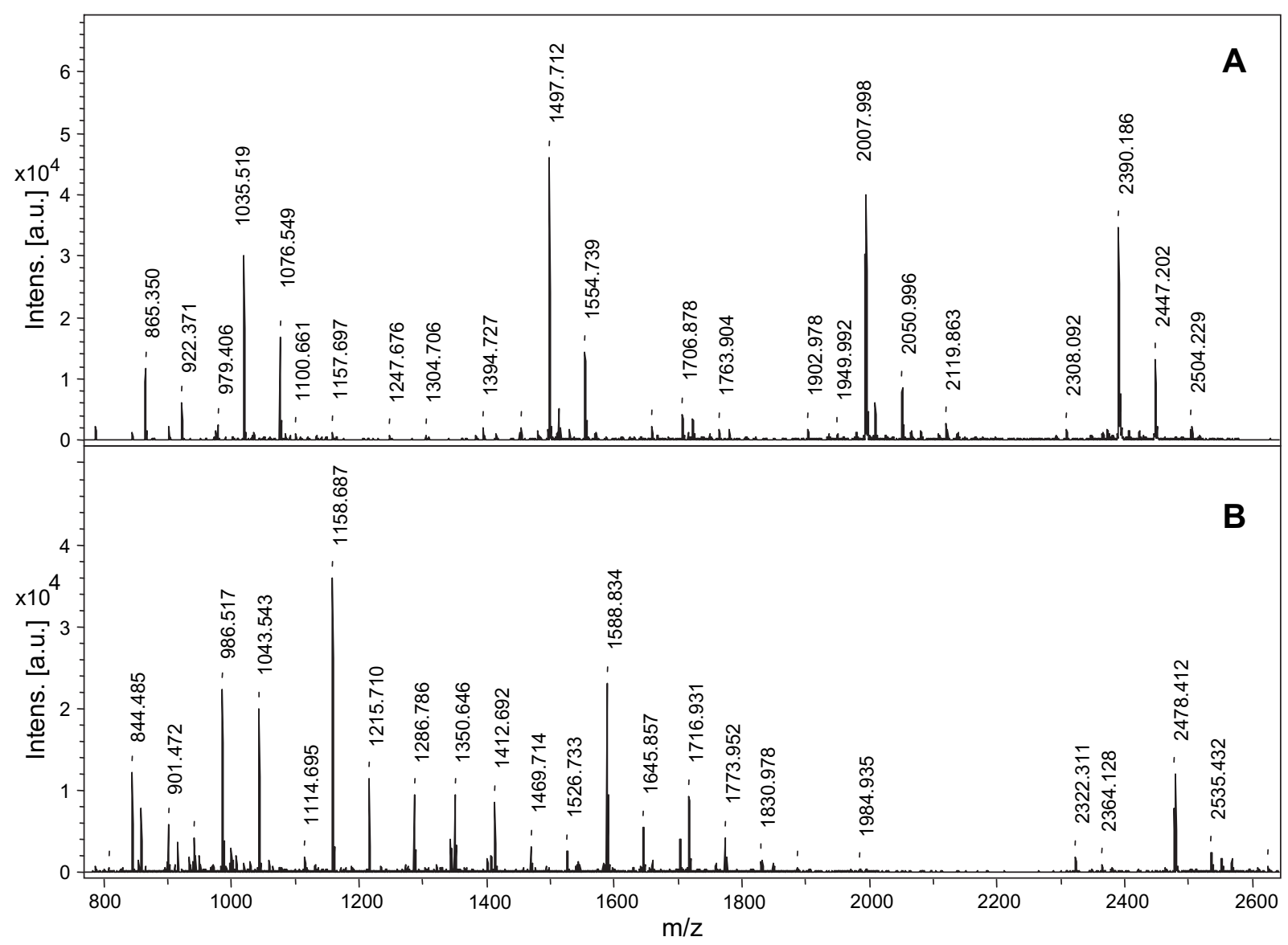

Fig. 1. MALDI-TOF mass spectra of tryptic digests from purified A) asclepain cI and B) asclepain cII, $m / z$ values of prominent peaks are indicated in each graphic.

dyad. For these enzymes, the residue of cysteine is essential for their enzymatic activity $[8,9]$. The clan CA is the largest clan of cysteine peptidases with the papain-like family $(\mathrm{C} 1)$ being the most studied. Family $\mathrm{C} 1$ has been subdivided into subfamily C1A, which comprises peptidases that contain disulfide bridges and accumulate in vesicles, the vacuole, or the apoplast, and family $\mathrm{C} 1 \mathrm{~B}$, which comprises peptidases that lack disulfide bridges and are located in the cytoplasm [8]. Papain-like cysteine peptidases are synthesized as inactive proenzymes with $\mathrm{N}$-terminal propeptide regions, which are removed upon activation. In addition to its inhibitory role, the propeptide is required for proper folding of the newly synthesized enzyme and its stabilization in denaturing $\mathrm{pH}$ conditions. Residues within the propeptide region also play a role in the transport of the proenzyme to lysosomes or acidified vesicles [10].

Plant peptidases in recent years have been the subject of intensive research and have been proposed as part of several important processes [11] such as plant development [12], root symbiosis [13], plant defense against pathogens [14] and insects [3,15], programmed cell death [16], and seed germination [17]. Papain-like peptidases are implicated in pathogen perception, disease resistance signaling, defense against insects, and senescence [11]. Despite the large amount of information gathered in recent years on plant peptidase function, little is known about the functions of latex peptidases. Agrawal and coworkers [15] in phylogenetically independent analyses have demonstrated a positive correlation between Asclepias spp. latex exudation and cysteine peptidase activity, thus sharing a correlated evolutionary history. It is possible that latex cysteine peptidases act in the degradation of proteins during laticifer development or promotion of coagulation or as responsible for strong toxicity.
In the current paper we report a new approach directed at the selective characterization of papain-like peptidase isoenzymes. The methodology used included techniques of protein purification, molecular biology, and proteomics. For this purpose latex of Asclepias curassavica, which is known to present two cysteine endopeptidases that share some physical and biochemical features-asclepain cI (acI) and asclepain cII (acII) $[2,18]$, was taken as starting material.

\section{Materials and methods}

\subsection{Plant material}

A. curassavica L., "scarlet milkweed", (Asclepiadaceae) is an erect, evergreen perennial subshrub [19]. Native to South America, A. curassavica has become a naturalized weed in tropical and subtropical areas distributed throughout the world. This species presents non-articulated laticifers in all organs. Latex was obtained from plants grown in La Plata, Province of Buenos Aires, Argentina. A voucher specimen (UNR 1130) has been deposited at the UNR herbarium (Faculty of Agricultural Sciences, University of Rosario, Argentina).

\subsection{Peptidases isolation and purification}

Crude extract (CE) was prepared by ultracentrifugation of latex obtained by superficial incisions of petiols, according to Liggieri and coworkers [2]. AcI and acII peptidases were purified from the CE by cation exchange chromatography following the method of Liggieri and coworkers [2]. 
Table 1

Primer design for Asclepiadaceae latex endopeptidase molecular cloning. A) and B) show primers design with $\mathrm{N}$-terminal sequences. C) and D) show primers design with catalytic site sequences.

A)

Primer NTapo1 (5'-GTTGAATTGCCAGATTCTGTAGATTGG- 3')

Enzyme

Araujiain h II

$\mathrm{N}$-Terminal sequence

VPDSIDWREKDAVLPIRNQGQ

LPESVDWRKKNLVFPVRNQGQ

LPNSVDWROKGVVFPIRDOGK

LPSFVDWRQKGVVFPIRNQGQ

VELPDSVDWREKGVVFPIRNQGK

LPNSVDWROKGVVSAIRNQGK

LPDSVDWRKKNLVFPVRNQGK

References

[25]

[25]

[2]

[18]

[23]

[26]

[24]

Morrenain o II

B)

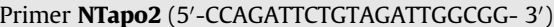

Enzyme

$\mathrm{N}$-Terminal sequence

VPDSIDWREKDAVLPIRNQGQ

LPESVDWRKKNLVFPVRNQGQ

LPSFVDWRQKGVVFPIRNQGQ

LPDSVDWREKGVVFPIRNOGK

LPNSVDWRQKGVVFPIRDQGK

LPNSVDWRQKGVVSAIRNQGK

LPDSVDWRKKNLVFPVRNOGK

References

[25]

[25]

[18]

[22]

[2]

[26]

[24]

Morrenain o II

C)

Primer CAapo1 5'-CCTATCAGAAATCAAGGAAAATGTGGGAGTTGCTGG-3'

Enzyme

Protein sequence

Asclepain $\mathrm{f}$

Asclepain c I

LPDSVDWREKGVVFPIRNQGKCGSCWTFSA

References

LPNSVDWRQKGVVFPIRDQGKCGSCWTFSA

[23]

LPSFVDWRQKGVVFPIRNQGQCGSCWTFSA

[2]

[18]

D)

Primer CAapo2 5'-ATCAAGGAAAATGTGGGAGTTGCTGG-3'

Enzyme Protein sequence

Asclepain $\mathrm{f}$

Asclepain c I

References

LPDSVDWREKGVVFPIRNQGKCGSCWTFSA

[23]

LPNSVDWROKGVVFPIRDOGKCGSCWTFSA

LPSFVDWRQKGVVFPIRNQGQCGSCWTFSA

Asclepain c I

Degenerated primers were designed encoding conserved $\mathrm{N}$-terminal and active site sequences from Asclepiadaceae latex endopeptidases (bold sequences) obtained by automated Edman's degradation. CAapo1 and CAapo2 were used as nested primers to improve the efficiency of amplification of specific cDNAs.

\subsection{SDS-PAGE analysis}

Purified samples of acI and acIl were analyzed by sodium dodecyl sulphate-polyacrylamide gel electrophoresis (SDS-PAGE) with tricine cathodic buffer in $10 \%$ polyacrylamide gels [20]. Gels were stained with Coomassie brilliant blue R-250.

\subsection{Peptide mass fingerprint (PMF) analysis by MALDI-TOF MS}

Bands corresponding to purified peptidases were cut out, washed with milli $\mathrm{Q}$ water and acetonitrile several times to remove dye and dried under vacuum. The gel fragments were treated with $0.1 \mathrm{M} \mathrm{NH}_{4} \mathrm{HCO}_{3}$ containing $10 \mathrm{mM}$ DTT for $30 \mathrm{~min}$ at $37{ }^{\circ} \mathrm{C}$ centrifuged, washed with acetonitrile for $5 \mathrm{~min}$, and then incubated in darkness in $0.1 \mathrm{M} \mathrm{NH}_{4} \mathrm{HCO}_{3}$ with $50 \mathrm{mM}$ iodoacetamide for 20 min at $25{ }^{\circ} \mathrm{C}$ for Cys sulfhydryl alkylation. Digestions were carried out with $4 \mathrm{ng} / \mu \mathrm{l}$ trypsin during $12 \mathrm{~h}$ at $37^{\circ} \mathrm{C}$. The peptides obtained were recovered by extraction with $0.5 \mathrm{ml} / \mathrm{ml}$ of acetonitrile (ACN), dried in a SpeedVac vacuum centrifuge and redissolved in $1 \mathrm{ml} / 1$ of trifluoroacetic acid (TFA). Each sample was spotted on a Ground Steel plate and mixed with freshly prepared matrix solution ( $10 \mathrm{mg} / \mathrm{ml}$ of $\alpha$-cyano-4-hydroxycinnamic acid in aqueous solution containing $30 \% \mathrm{ACN}$ and $0.1 \% \mathrm{TFA}$ ). PMFs were obtained by MALDI-TOF MS with UltraFlex MALDI-TOF mass spectrometer (Bruker Daltonics, Bremen, Germany). Peptide masses were acquired with Flex Control Software in a range of $c a .1000-3500 \mathrm{~m} / z$. External calibration was performed using peptide calibrants.

MASCOT search tool (URL http://www.matrixscience.com) was used for identification of tryptic maps. Search parameters: (1) Type of search, Peptide Mass Fingerprint; (2) Enzyme, trypsin; (3) Database, SwissProt 55.2; (4) Taxonomy, Viridiplantae; (5) Variable modifications, Carbamidomethyl (C), Oxidation (M); (6) Mass values, Monoisotopic; (7) Peptide Mass Tolerance: \pm 1000 ppm; (8) Peptide Charge State, $1+$. Probability Based Mowse Score: Protein score is $-10^{*} \log (\mathrm{P})$, where $\mathrm{P}$ is the probability that the observed match is a random event. Protein scores greater than 56 were considered significant $(p<0.05)$.

\section{5. cDNA cloning}

Total RNA was isolated from two latex drops, obtained by superficial incisions of petioles, using the RNAeasy Plant Mini Kit (Qiagen, Barcelona, Spain) following the manufacturer's protocol. Double-stranded cDNA was synthesized by $3^{\prime}$ rapid amplification of cDNA ends - polymerase chain reaction - 3'RACE-PCR [21]. cDNA template was generated with First Strand cDNA Synthesis Kit for RT-PCR, AMV (avian myeloblastosis virus) reverse transcriptase (Roche Applied Science, Mannheim, Germany) and $\mathrm{R}_{0} \mathrm{R}_{1}$ polidT primer (5'-CCGGAATTCACTGCAGGGTACCCAATACGACTCACTATAG GGCTTTTTTTTTTTTTTTTT- $\left.3^{\prime}\right)$. Reaction was carried out in a thermal cycler XPCycler (Bioer Technology Co., Ltd, Hangzhou, China) following the program: $10 \mathrm{~min}$ at $25^{\circ} \mathrm{C}, 120 \mathrm{~min}$ at $42{ }^{\circ} \mathrm{C}, 5 \mathrm{~min}$ at $99{ }^{\circ} \mathrm{C}$, and 5 min at $10{ }^{\circ} \mathrm{C}$. cDNA was PCR-amplified with the following specific oligonucleotides: NtApo1 (5'-GTTGAATTGCCAGA TTCTGTAGATTGG-3'), NtApo2 (5'-CCAGATTCTGTAGATTGGCGG-3') or degenerated primers $\mathrm{Nd}_{1-8}\left(5^{\prime}\right.$-yTkCCdGATTCCGATGTTTGGmG-3', $\mathrm{y}=\mathrm{C}$ or $\mathrm{T}, \mathrm{m}=\mathrm{A}$ or $\mathrm{C}$ and $\mathrm{k}=\mathrm{G}$ or $\mathrm{T}$ ), and the adaptor primer $\mathrm{R}_{0}$ (5'-CCGGAATTCACTGCAG-3'). The PCR mixture containing $5 \mu \mathrm{l}$ of the cDNA previously obtained, 25 pmol of adaptor primer and $25 \mathrm{pmol}$ of one of the specific primers, $20 \mathrm{nmol}$ of deoxynucleotide triphosphates, $5 \mathrm{U}$ EcoTaq/Thermus aquaticus polimerase, $5 \mu \mathrm{l}$ buffer EcoTaq $10 \times, 2 \mu \mathrm{l} \mathrm{MgCl}_{2} 50 \mathrm{mM}$ (all of above reagents purchased from Ecogen, Barcelona, Spain) was subjected to reaction in the same thermal cycler following the program: $1 \times\left(5 \mathrm{~min}\right.$ at $95{ }^{\circ} \mathrm{C}$; $15 \mathrm{~min}$ at $\left.72{ }^{\circ} \mathrm{C}\right) ; 30 \times\left(1 \mathrm{~min}\right.$ at $94{ }^{\circ} \mathrm{C} ; 1 \mathrm{~min}$ at $46{ }^{\circ} \mathrm{C} ; 2 \mathrm{~min}$ at $\left.72{ }^{\circ} \mathrm{C}\right) ; 1 \times\left(15 \mathrm{~min}\right.$ at $\left.72{ }^{\circ} \mathrm{C}\right) ; 1 \times\left(16 \mathrm{~h}\right.$ at $\left.10^{\circ} \mathrm{C}\right)$.

Design of specific primers was performed from most conserved amino acid sequences of peptidases ( $\mathrm{N}$-terminal and active site catalytic Cys containing regions) from the Asclepiadaceae family [2,18,22-26]. Nucleotide sequences corresponding to such amino acid sequences were obtained with Backtranslation Tool, available on the WEB (http://www.entelechon.com/bioinformatics/backtranslation. php?lang=eng).

To improve the efficiency of amplification of specific cDNAs a second set of PCR cycles was carried out using two combinations of nested primers: asclepiadaceae-specific primer CAapo1 $\left(5^{\prime}-\right.$ CCTATCAGAAATCAAGGAAAATGTGGGAGTTGCTGG-3') and adaptor primer R1 (5'-GGTACCCAATACGACTCACTATAGGGC-3'), and asclepiadaceae-specific primer CAapo2 (5'-ATCAAGGAAAATGTGGGA GTTGCTGG-3') with the same adaptor primer (R1).

PCR products were visualized on $20 \mathrm{~g} / \mathrm{l}$ agarose gel as bands of about $760 \mathrm{bp}$, the expected size based on known molecular masses of papain-like peptidases, and extracted by QIAEX II Agarose Gel Extraction (Qiagen). The isolated cDNA was inserted into pGEM-T Easy vector (Promega Biotech Iberica, Alcobendas, Spain). Escherichia coli XL1-Blue competent cells were transformed and cultured on LB plates with $100 \mu \mathrm{g} / \mathrm{ml}$ ampicillin, $112 \mu \mathrm{g} / \mathrm{ml}$ IPTG and $80 \mu \mathrm{g} / \mathrm{ml}$ $\mathrm{X}$-Gal overnight at $37^{\circ} \mathrm{C}$. White colonies were selected for transfer to LB medium with $50 \mu \mathrm{g} / \mathrm{ml}$ ampicillin and cultured overnight at $37{ }^{\circ} \mathrm{C}$; afterwards plasmids with inserts were extracted using commercial purification kit (GFX Micro Plasmid Prep Kit, GE HealthCare Biosciences, Uppsala, Sweden). Purified plasmids were 


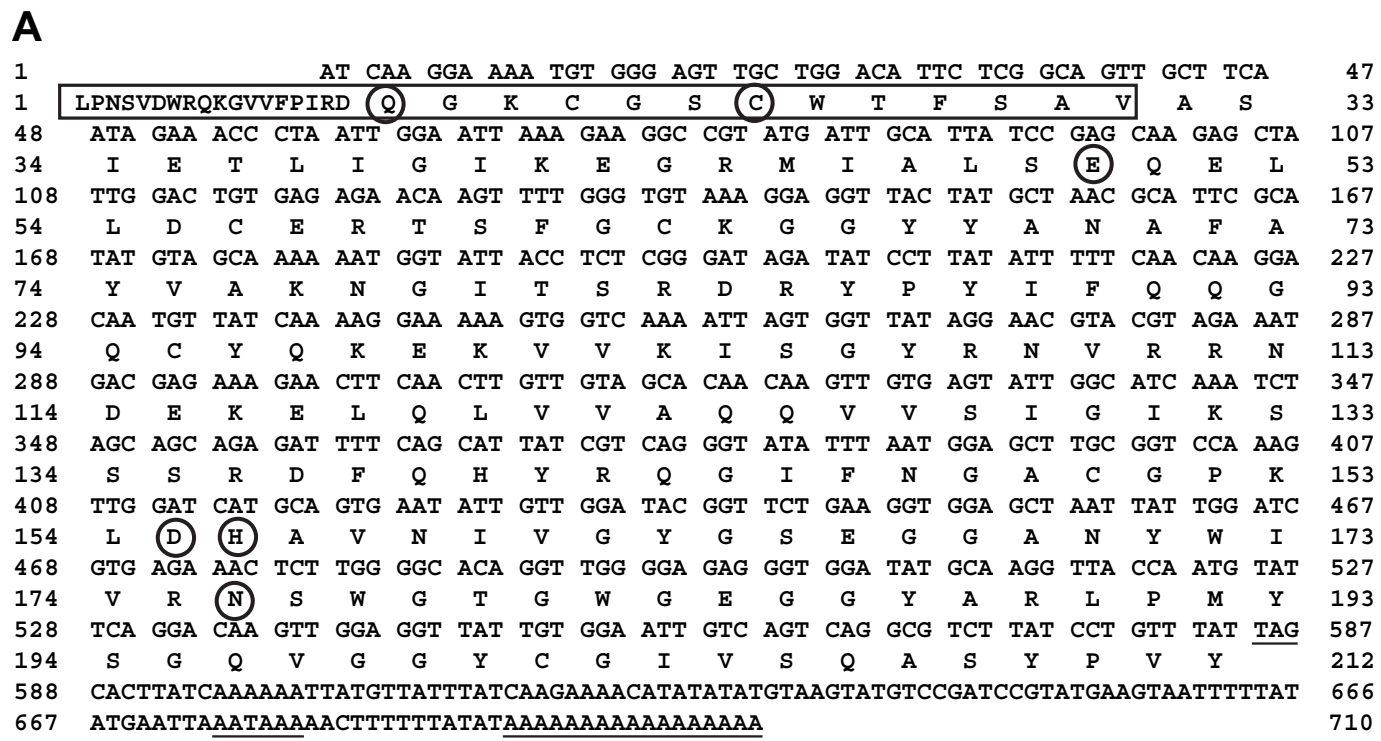

B

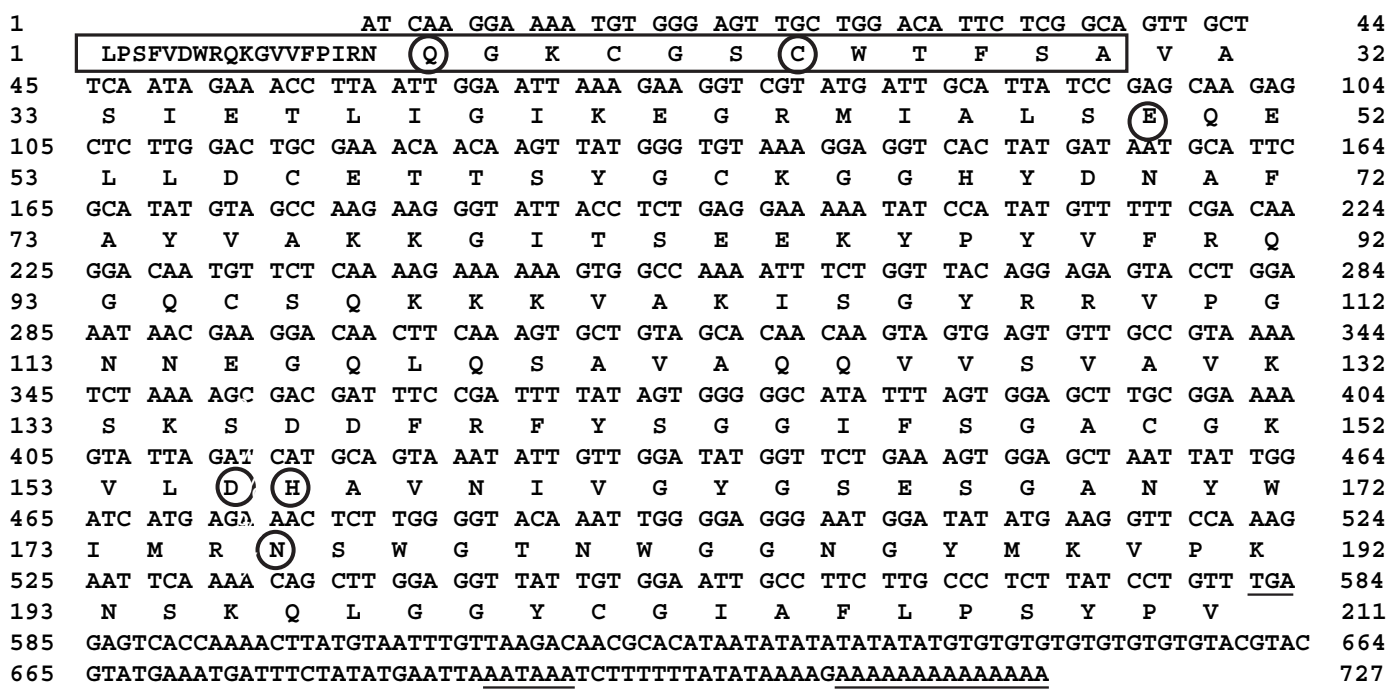

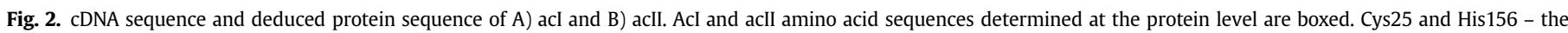
catalytic dyad - and other residues that help to stabilize the dyad are circled. Stop codon, polyadenylation signal and polyA tail are underlined.

digested with EcoRI restriction enzyme (2 U), identified by PCR (program and reaction mixtures same as above, using CAapo1 and $\mathrm{R} 1$ primers) and analyzed by electrophoresis on $10 \mathrm{~g} / \mathrm{l}$ agarose gel. Positive plasmids were sequenced by the Sequencing Services of Veterinary Faculty, Autonomous University of Barcelona (Barcelona, Spain). Chromatograms were analyzed with the software Chromas v2.13 (Technelysium Pty. Ltd).

\subsection{Obtaining the full-length sequence of mature acI and acI}

cDNA sequences obtained from the clones were analyzed with Translating Blast Service (Translated query - Translated db [tblastx] tool) that converts a nucleotide query sequence into protein sequences in all 6 reading frames and then compares this to an NCBI nucleotide database which has been translated in all six reading frames (http://blast.ncbi.nlm.nih.gov/Blast.cgi?PAGE=Translations \&PROGRAM =blastx\&BLAST_PROGRAMS=blastx\&PAGE_TYPE= BlastSearch\&SHOW_DEFAULTS $=$ on \&BLAST_SPEC $=$ \&LINK_LOC $=$
blasttab\&LAST_PAGE=blastn). In translated Blast NCBInr database was restricted to the Viridiplanteae kingdom in order to identify the presence of plant cysteine endopeptidase amino acid sequence conserved elements.

The translated sequences obtained were subjected to theoretical tryptic digestion by means of SequenceEditor 3.1 software (Bruker Daltonics, Biotools 3.1). Comparison of this theoretical mass maps with empirical PMF of purified peptidases (Section 2.4.) helped to identify each peptidase. Then N-terminal sequences previously obtained by Edman $[2,18]$ were overlapped to the partial sequence obtained by cloning and thus the complete sequences of the mature enzymes were obtained.

\subsection{Amino acid sequence alignment and phylogenetic trees construction}

Multiple sequence alignment was performed with CLUSTAL W2 [27] and Basic Local Alignment from the National Center for 
Biotechnology Information (URL http://blast.ncbi.nlm.nih.gov/ Blast.cgi), conserved domains (CD) were identified with NCBI's CD-Search service (URL http://www.ncbi.nlm.nih.gov/Structure/ cdd/wrpsb.cgi, search performed against database: cdd-27036 PSSMs) [28] and evolutionary distance model was constructed with PSI-BLAST tool, that allow construction of guide trees between sequences with more than $75 \%$ mismatched amino acids (Grishin), tree method: neighbor joining, distance: Grishin (protein).

\subsection{Theoretical properties and modeling}

Theoretical physicochemical properties of the deduced amino acid sequences ( $\mathrm{pI}, \mathrm{Mw}$ and molar extinction coefficient) were predicted by the GPMAW v6.0 software algorithms (Lighthouse data, DK-5230 Odense M, Denmark). Data obtained were compared with those previously experimentally determined $[2,18]$. Putative phosphorylation motifs were searched with NetPhos 2.0 server (URL http://www.cbs.dtu.dk/services/NetPhos/).

\section{Results and discussion}

\subsection{PMF analysis}

Asclepain cI and cII, two peptidases isolated from latex of $A$. curassavica, were purified by cation exchange chromatography. Purified proteins separated by SDS-PAGE were cleaved in situ with the residue-specific peptidase trypsin and hydrolyzed derived peptides were eluted. Trypsin produces a series of peptides of different molecular mass characteristic of each particular protein. PMF spectra of acI and acII are shown in Fig. $1 \mathrm{~A}$ and B, respectively. The peptide map analysis showed the enzymes have no equivalent peptides, despite their high degree of sequence identity. The peptide profiles of the query proteins were compared with theoretical peptide libraries generated from sequences in the MASCOT database in order to identify the studied proteins. Usually as few as three to four masses that match closely are often enough to obtain a significant match [29] but no identification was possible due to the limited amount of information concerning Asclepiadaceae latex cysteine proteinases deposited in the available databases.

\subsection{Molecular cloning of acI and acII cDNAs and characterization of deduced amino acid sequence}

Degenerated primers were designed encoding conserved Nterminal and active site sequences obtained by automated Edman's degradation of asclepain c I [2] and asclepain c II [18] from $A$. curassavica L.; asclepain f [23] from Asclepias fruticosa L. [syn: Gomphocarpus fruticosus] (accession number: FM201283); araujiain h II and h III [25] from Araujia hortorum; morrenain o II [24] from Morrenia odorata and funastrain c II [26] from Funastrum clausum (Table 1); all species belonging to the Asclepiadaceae family. These peptidase sequences were selected to ensure that the primers designed could be useful in a general way for cloning any cysteine peptidase from latex of the Asclepiadaceae family. Furthermore, if one considers the high degree of conservation of the amino terminal sequences, as well as, the conserved surroundings of the catalytic Cys25 of papain-like endopeptidases, it is very likely that the primers Ntapo1, Ntapo2, Capo1 and Capo2 could be useful for the molecular cloning of other members of the C1A subfamily.

Total RNA was isolated from latex of A. curassavica and cDNAs encoding internal segments of two different putative cysteine endopeptidases were obtained by RT and 3'RACE-PCR methods (GenBank accession number: FM877966 and FM877967). Twelve cDNA sequences obtained from different clones were analyzed, and alignment results revealed two consensus sequences of 710 and
727 nucleotides with $82 \%$ identities [score (S): 590 , expected value $(E): 1 \times \mathrm{e}^{-172}$ ] among them, both containing one stop codon, a polyA-signal and a poly(A) sequence (Fig. $2 \mathrm{~A}$ and $\mathrm{B}$ ). The nucleotide sequences translated in all six reading frames produced significant alignments with mRNA of cysteine endopeptidases isolated from latex. The shorter sequence ( 710 nucleotides) showed high degree of identity with asclepain $\mathrm{f}$, of $A$. fruticosa (74\% identities, $\left.S=360, E=9 \times \mathrm{e}^{-98}\right)$, papaya proteinase omega and proteinase IV from Carica papaya (46\% identities, $S=134$, $E=1 \times \mathrm{e}^{-60}$ and $47 \%$ identities, $S=141, E=1 \times \mathrm{e}^{-56}$, respectively) while the larger nucleotide sequence (727 nucleotides) exhibits such high identity only with asclepain $\mathrm{f}$ ( $86 \%$ identities, $S=315$, $\left.E=1.9 \times \mathrm{e}^{-89}\right)$.

To further confirm that the cDNA from latex codes for acI and acII and not for other cysteine peptidases present in latex, the theoretical mass maps of the translated sequences were compared with those of the purified acI and acII. The experimentally determined masses of peptides derived from both peptidases match well (0.6 Da of mass tolerance) with those in silico fragments generated by the simulated digestion of the putative sequences (10 and 8 coincident peptides for acI and acII, respectively; Table 2). The resultant peptide fragments that matched covered a $50 \%$ and $43 \%$ of the acI and acII entire sequences, respectively. Thus, confirming the sequence of 710 and 727 nucleotides correspond to acI and acII, respectively. The proposed sequences for the mature enzymes are shown in Fig. 2A and B, containing 212 (acI) and 211 (acII) amino acids and including those residues coming from the $\mathrm{N}$-terminal sequence determined at the protein level.

When acI and acII sequences were analyzed by GPMAW v6.0 the calculated molecular masses were 23513 and 23057 Da, which are of the same order of those obtained for other peptidases from Asclepiadaceae $[18,30]$; the molar extinction coefficients were 48010 and $44170 \mathrm{M}^{-1} \mathrm{~cm}^{-1}$, respectively. The calculated pI values were 9.78 for acl and 9.82 for acII, in agreement with the experimental values, higher than 9.3 reported by Liggieri and coworkers $[2,18]$. Then, acI and acII are more basic than papain with a pI of 8.75

Table 2

Theoretical and experimental masses of trysin-digested peptides of $\mathbf{A}$ ) asclepain cl and $\mathbf{B})$ asclepain cII. A.

\begin{tabular}{llll}
\hline $\begin{array}{l}\text { Experimental } \\
\text { PMF }\end{array}$ & $\begin{array}{l}\text { Theoretical } \\
\text { PMF }\end{array}$ & $\begin{array}{l}\text { Fragment } \\
\text { position }\end{array}$ & Peptide fragment sequence \\
\hline A) & & & \\
$m / z$ & $m / z$ & & \\
1120.55 & 1120.65 & $104-112$ & ISGYRNVRR \\
1148.58 & 1148.55 & $143-153$ & QGIFNGACGPK \\
1394.73 & 1394.67 & $65-77$ & GGYYANAFAYVAK \\
1497.71 & 1497.65 & $176-189$ & NSWGTGWGEGGYAR \\
1706.87 & 1706.81 & $45-58$ & MIALSEQELLDCER \\
1722.88 & 1722.79 & $86-98$ & YPYIFQQGQCYQK \\
1936.97 & 1936.90 & $84-98$ & DRYPYIFQQGQCYQK \\
1979.00 & 1979.93 & $86-100$ & YPYIFQQGQCYQKEK \\
2065.03 & 2065.93 & $59-77$ & TSFGCKGGYYANAFAYVAK \\
2390.19 & 2390.19 & $154-175$ & LDHAVNIVGYGSEGGANYWIVR \\
B) & & & \\
$m / z$ & $m / z$ & & \\
1019.51 & 1019.53 & $1-8$ & LPSFVDWR \\
1043.52 & 1043.63 & $9-17$ & QKGVVFPIR \\
1412.67 & 1412.66 & $65-77$ & GGHYDNAFAYVAK \\
1540.76 & 1540.75 & $65-78$ & GGHYDNAFAYVAKK \\
1588.80 & 1588.80 & $79-91$ & GITSEEKKYPYVFR \\
2322.21 & 2322.24 & $110-132$ & VPGNNEGQLQSAVAQQVVSVAVK \\
2478.29 & 2478.34 & $109-132$ & RVPGNNEGQLQSAVAQQVVVAVK \\
2551.18 & 2551.24 & $153-175$ & VLDHAVNIVGYGSESGANYWIMR \\
\hline
\end{tabular}

Cysteines have been treated with iodoacetamide to form carbamidomethyl-cysteine (Cys-CAM). For theoretical PMF Cys-CAM, oxidized Cys and monoisotopic masses of the occurring amino acid residues were considered. The experimental and theoretical mass values matches were selected with a mass tolerance of 0.6 Da. 


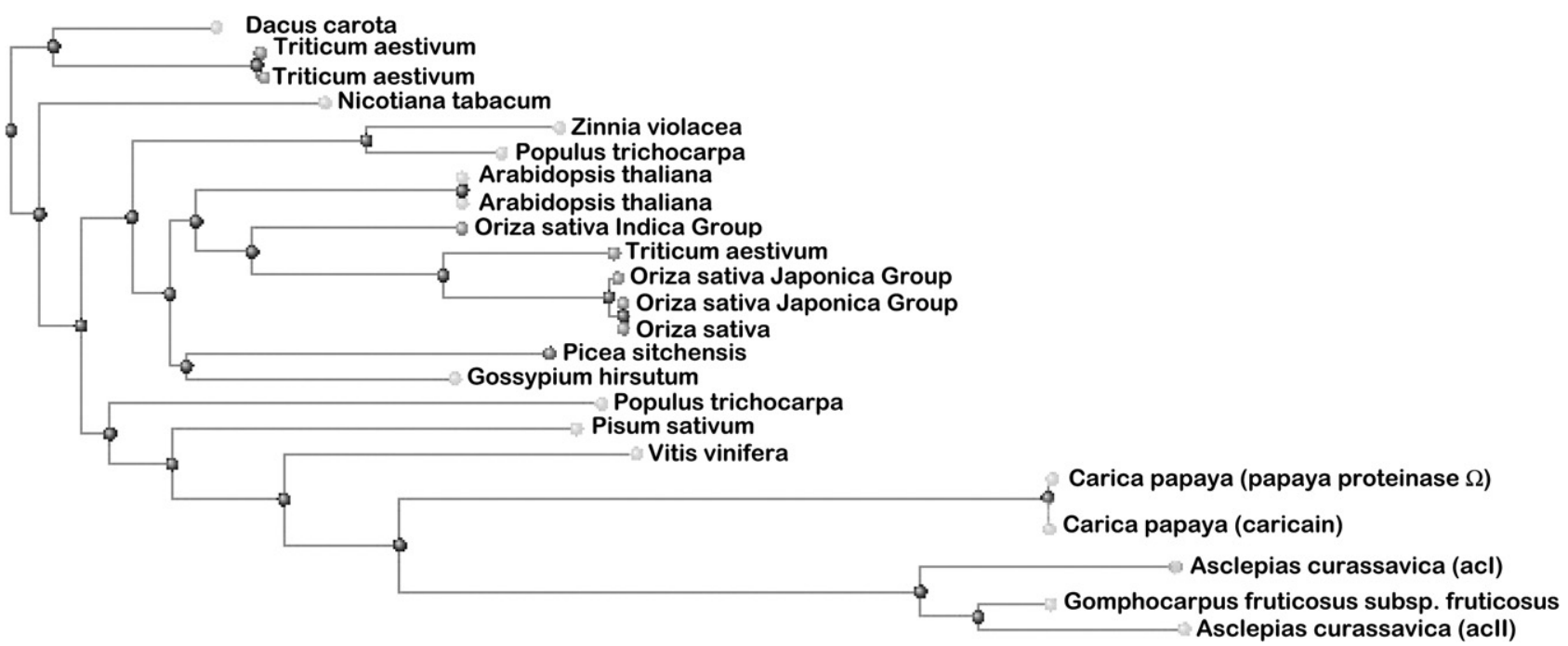

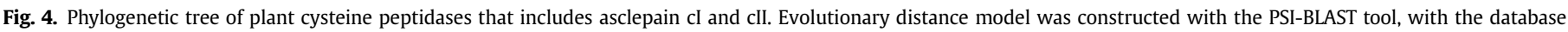
restricted to the Viridiplanteae kingdom. Tree method used: neighbor joining, distance according to Grishin (protein) retricted to 0.5 .

moreover this cluster contained two distinct subgroups: acI on one side and acll and asclepain $\mathrm{f}$ ( $A$. fruticosa) on the other. It is noteworthy that the peptidases from latex (Asclepiadaceae and Caricaceae family) formed a group apart, that would indicate a common ancestor

\subsection{Future perspectives}

Latices from Asclepiadaceae have been used in folk medicines as antiparasitic agents against gastrointestinal nematodes and in wound healing in addition to other ailments. The pharmacological actions of these milky latices have been attributed to the presence of cysteine peptidases [35-37]. Recently it was established by Shivaprasad and co-workers [37] that the cysteine proteases from A. curassavica latex affect haemostasis by exhibiting thrombin like activity mediated by specific cleavage of fibrinogen. This is considered as the basis for the use of plant latex traditionally to stop bleeding on fresh cuts. Examples of other potential biomedical uses are: gastric phytobezoar [38], gastric antiulcerogenic [39], antitumoral agent [40] among a wide variety of uses of papain-like peptidases that have not yet been investigated for acI and acII. Whereas, some potential biotechnological applications comprise the use of these enzymes as meat tenderizers (such as Panol ${ }^{\circledR}$ Purified Papain, Liquipanol ${ }^{\circledR}$ T100 available in the market), component of detergent formulations [41], surfactants synthesis [42] among others.

\section{Conclusions}

Peptidases asclepain cI and asclepain cII from A. curassavica are two isoenzymes belonging to the C1A subfamily (MEROPS database nomenclature). This subfamily is composed of papain-like cysteine peptidases, including some peptidases of bacteria, protozoa, arthropod, mammalian and plant origin; most members of the subfamily are endopeptidases. In addition to its peptidase activity acI and acII hydrolyze a wide variety of synthetic esters and acI also hydrolyzes amide bonds $[2,18]$. In this paper we have designed a set of primers based on highly conserved sequences of Asclepiadaceae latex cysteine endopeptidases potentially useful for cloning other latex peptidases of the family $\mathrm{C} 1 \mathrm{~A}$. We have also presented the partial nucleotide sequence of two cysteine peptidases cDNA cloned from RNA of A. curassavica latex. By PMF analysis of acI and
acIl we have confirmed which cloned cDNA correspond to each isoenzyme. Additionally PMF allowed us to complete the sequences of the mature peptidases by adding the $\mathrm{N}$-terminus determined by Edman's method. PMF could be adopted as an excellent tool to differentiate, in a fast and unequivocal way, peptidases with very similar physicochemical and functional properties. In this sense PMF has advantages on other conventional methods (for instance enzyme kinetics) that are time consuming and afford less reliable results. The robustness of the method even allowed the differentiation of the homologue isoenzymes of the latex of A. curassavica.

Based on previous substrate specificity studies and due to the kinship of acl and acIl with papain, these enzymes are promising for other biomedical and biotechnological applications.

\section{Acknowledgment}

This work was supported by grants from ANPCyT (PICT 15-38088), CONICET (PIP 2813), University of La Plata, Argentina, as well as from CYTED IV.22. W.D.O. and S.V.C. are members of the CONICET Research Career program, C.L. is member of the CIC Support Professional Career program.

\section{Appendix. Supplementary material}

Supplementary data associated with this article can be found in the online version at doi:10.1016/j.biochi.2009.07.017.

\section{References}

[1] C.D.T. Freitas, J.S. Oliveira, M.R.A. Miranda, N.M.R. Macedo, M. Pereira Sales, L.A. Villas-Boas, M.V. Ramos, Enzymatic activities and protein profile of latex from Calotropis procera, Plant Physiol. Biochem. 45 (2007) 781-789.

[2] C. Liggieri, M.C. Arribére, S.A. Trejo, F. Canals, F.X. Avilés, N. Priolo, Purification and biochemical characterization of asclepain c I from the latex Asclepias curassavica L. Protein J. 23 (2004) 403-411.

3] K. Konno, C. Hirayama, M. Nakamura, K. Tateish, Y. Tamura, M. Hattori, K. Kdino, Papain protects papaya trees from herbivorous insects: role of cysteine proteases in latex, Plant J. 37 (2004) 370-378.

[4] A. Kush, E. Goyvaerts, M.L. Chye, N.H. Chua, Laticifer-specific gene expression in Hevea brasiliensis (rubber tree), Proc. Natl. Acad. Sci. U.S.A. 87 (1990) 1787-1790.

[5] F. Fiorillo, C. Palocci, S. Soro, G. Pasqua, Latex lipase of Euphorbia characias L.: an aspecific acylhydrolase with several isoforms, Plant Sci. 172 (2007) $722-727$.

[6] R. Ghosh, S. Chakraborty, C. Chakrabarti, J.K. Dattagupta, S. Biswas, Structural insights into the substrate specificity and activity of ervatamins, the 
papain-like cysteine proteases from a tropical plant, Ervatamia coronaria, FEBS J. 275 (2008) 421-434.

[7] A.J. Barrett, N.D. Rawlings, J.F. Woessner, Handbook of Proteolytic Enzymes, Academic Press, London, 1998, pp. XXV.

[8] N.D. Rawlings, F.R. Morton, C.Y. Kok, J. Kong, A.J. Barrett, MEROPS: the peptidase database, Nucleic Acids Res. 36 (2008) D320-D325.

[9] L. Polgár, in: A.J. Barret, N.D. Rawlings, J.F. Woessner (Eds.), Handbook of Proteolytic Enzymes, Elsevier, Amsterdam, 2004, pp. 1072-1079.

[10] N. Rawlings, A. Barrett, Introduction the clans and families of cysteine endopeptidases, in: A. Barrett, N. Rawlings, J. Woessner (Eds.), Handbook of Proteolytic Enzymes, second ed. Elsevier Academic Press, Amsterdam, 2004, pp. 1051-1071.

[11] R.A.L. van der Hoorn, Plant proteases: from phenotypes to molecular mechanisms, Annu. Rev. Plant Biol. 59 (2008) 191-223.

[12] B. Bölter, A. Nada, H. Fulgosi, J. Soll, A chloroplastic inner envelope membrane protease is essential for plant development, FEBS Lett. 580 (2006) 789-794.

[13] N. Takeda, C. Kistner, S. Kosuta, et al., Proteases in plant root symbiosis, Phytochem 68 (2007) 111-121 T.

[14] J.R. Pagano, F.F. Mendieta, G. Muñoz, R. Daleo, M.G. Guevara, Roles of glycosylation on the antifungal activity and apoplast accumulation of StAPs (Solanum tuberosum aspartic proteases), Int. J. Biol. Macromol 41 (2007) 512-520.

[15] A.A. Agrawal, M.J. Lajeunesse, M. Fishbein, Evolution of latex and its constituent defensive chemistry in milkweeds (Asclepias): a phylogenetic test of plant defense escalation, Entomol. Exp. Appl. 128 (2008) 126-138.

[16] H.J. Chen, D.J. Huang, W.C. Hou, J.S. Liu, Y.H. Lin, Molecular cloning and characterization of a granulin-containing cysteine protease SPCP3 from sweet potato (Ipomoea batatas) senescent leaves, J. Plant Physiol. 163 (2006) 863-876.

[17] S. Sheokand, P. Dahiya, J.L. Vincent, N.J. Brewin, Modified expression of cysteine protease affects seed germination, vegetative growth and nodule development in transgenic lines of Medicago truncatula, Plant Sci. 169 (2005) 966-975.

[18] C. Liggieri, W.D. Obregón, S.A. Trejo, N. Priolo, Biochemical analysis of a papain-like protease isolated from the latex of Asclepias curassavica L. Acta Biochim. Biophys. Sin. 41 (2) (2009) 154-162.

[19] M.J. Dimitri, Enciclopedia Argentina de Agricultura y Jardinería Editorial, Vol. 1, Acme SACI, Buenos Aires, 1988, pp. 895.

[20] H. Shägger, G. Von Jagow, Tricine-sodium dodecyl sulfate-polyacrylamide gel electrophoresis for the separation of proteins in the range from 1 to $100 \mathrm{kDa}$, Anal. Biochem. 166 (1987) 368-379.

[21] M.A. Frohman, On beyond classic RACE (rapid amplification of cDNA ends), PCR Methods Appl. 4 (1) (1994) 40-58.

[22] S.A. Trejo, L.M.I. López, C.V. Cimino, N.O. Caffini, C.L. Natalucci, Purification and characterization of a new plant endopeptidase isolated from latex of Asclepias fruticosa L. (Asclepiadaceae), J. Protein Chem. 20 (4) (2001) 445-453.

[23] S.A. Trejo, L.M. López, N.O. Caffini, C.L. Natalucci, F. Canals, F.X. Avilés, Sequencing and characterization of asclepain $\mathrm{f}$ : the first cysteine peptidase cDNA cloned and expressed from Asclepias fruticosa latex, Planta 230 (2) (2009) 319-328.

[24] S.E. Vairo Cavalli, A. Cortadi, M.C. Arribére, P. Conforti, N.O. Caffini, N.S. Priolo, Comparison of two cysteine endopeptidases from latices of Morrenia brachystephana Griseb. and Morrenia odorata (Hook et Arn.) Lindley (Asclepiadaceae), Biol. Chem. Hoppe-Seyler 382 (2001) 879-883.

[25] W.D. Obregón, M.C. Arribére, S. Morcelle del Valle, C. Liggieri, N.O. Caffini, N.S. Priolo, Two new cysteine endopeptidases obtained from the latex of Araujia hortorum fruits, J. Protein Chem. 20 (2001) 17-25.

[26] S. Morcelle del Valle, N. Caffini, N. Priolo, Proteolytic properties of Funastrum clausum latex, Fitoterapia 75 (2004) 480-490.

[27] R. Chenna, H. Sugawara, T. Koike, et al., Multiple sequence alignment with the Clustal series of programs, Nucleic Acids Res. 31 (2003) 3497-3500.

[28] A. Marchler-Bauer, J.B. Anderson, P.F. Cherukuri, CDD: a conserved domain database for protein classification, Nucleic Acids Res. 33 (D) (2005) 192-196.

[29] J. Barrett, P.M. Brophy, J.V. Hamilton, Analysing proteomic data, Int. J. Parasitol. 35 (2005) 543-553.
[30] C. Sequeiros, M.J. Torres, S.A. Trejo, J.L. Esteves, C.L. Natalucci, L.M.I. López, Philibertain $\mathrm{g}$ I, the most basic cysteine endopeptidase purified from the latex of Philibertia gilliesii Hook. et Arn. (Apocynaceae, Protein J. 24 (2005) 445-453.

[31] S.D. Lewis, F.A. Johnson, J.A. Shafer, Effect of cysteine-25 on the ionization of histidine-159 in papain as determined by proton nuclear magnetic resonance spectroscopy. Evidence for a His-159-Cys-25 ion pair and its possible role in catalysis, Biochemistry 20 (1) (1981) 48-51.

[32] N.D. Rawlings, A.J. Barret, Evolutionary families of peptidases, Biochem. J. 15 (1993) 205-218

[33] F. Lecaille, E. Authié, T. Moreau, C. Serveau, F. Gauthier, G. Lalmanach, Subsite specificity of trypanosomal cathepsin L-like cysteine proteases. Probing the S2 pocket with phenylalanine-derived amino acids, Eur. J. Biochem. 268 (9) (2001) 2733-2741.

[34] Obregón, W.D., Liggieri, C., Morcelle, S., Trejo, S., Aviles, F.X., Priolo, N., Biochemical and Pmf MALDI-TOF analyses of three novel papain-like plant proteinases. Protein Pept. Lett. 16 (10), in press.

[35] G. Stepek, J.M. Behnke, D.J. Buttle, I.R. Duce, Natural plant cysteine proteinases as anthelmintics? Trends Parasitol. 20 (2004) 322-327.

[36] C.E. Salas, M.T.R. Gomes, M. Hernandez, M.T.P. Lopes, Plant cysteine proteinases: evaluation of the pharmacological activity, Phytochem. 69 (12) (2008) 2263-2269.

[37] H.V. Shivaprasad, R. Rajesh, B.L. Nanda, K.K. Dharmappa, B.S. Vishwanath, Thrombin like activity of Asclepias curassavica L. latex: action of cysteine proteases, J. Ethnopharmacol. 123 (2009) 106-109.

[38] A.J. Dwivedi, F. Chahin, S. Agrawal, J. Patel, M. Khalid, Y. Lakra, Gastric phytobezoar: treatment using meat tenderizer, Dig. Dis. Sci. 46 (2001) 1013-1015.

[39] C.F. Chen, S.M. Chen, S.Y. Chow, P.W. Han, Protective effects of Carica papaya Linn on the exogenous gastric ulcer in rats, Am. J. Chin. Med. 9 (1981) 205-212.

[40] A. Bellelli, M. Mattioni, V. Rusconi, M.L. Sezzi, L. Bellelli, Inhibition of tumo growth, invasion and metastasis in papain-immunized mice, Invasion Metastasis 10 (1990) 142-169.

[41] S.S. Khaparde, R.S. Singhal, Chemically modified papain for applications in detergent formulations, Bioresour. Technol. 78 (1) (2001) 1-4.

[42] S.R. Morcelle, C.S. Liggieri, M.A. Bruno, N. Priolo, P. Clapés, Screening of phytoproteases for the synthesis of arginine-based surfactants, J. Mol. Catal., B Enzym. 57 (2009) 177-182.

\section{Glossary}

acI: asclepain cl

acII: asclepain cIl

$A M V$ : avian myeloblastosis virus

$A C N$ : acetonitrile

blast: Basic Local Alignment Search Tool

$C D$ : conserved domains

$C E$ : crude extract

DTT: dithiothreitol

CDNA: complementary desoxyribonucleic acid

$E$ : expected value

IPTG: isopropyl-beta-D-thiogalactopyranoside

LB: Luria-Bertani Broth

MALDI TOF-MS: matrix assisted laser desortion ionization time of flight mass spectrometry

PCR: polymerase chain reaction

$P M F$ : peptide mass fingerprint

PSI-blast: Position-Specific Iterated-blast

$R A C E$ : rapid amplification of cDNA ends

RNA: ribonucleic acid

$R T$ : retrotranscription

$S$ : score

TFA: trifluoroacetic acid

$X$-gal: 5-bromo-4-chloro-3-indolyl- $\beta$-D-galactopyranoside 